\title{
The Political Imaginaries of 3D Printing: Prompting Mainstream Awareness of Design and Making
}

Jesse Adams Stein, Chancellor's Postdoctoral Research Fellow, University of Technology Sydney

jesse.stein@uts.edu.au

\section{Author Bio}

Dr Jesse Adams Stein is a Chancellor's Postdoctoral Research Fellow in the Faculty of Design, Architecture and Building, University of Technology Sydney. She is an interdisciplinary design researcher specializing in the relationship between technological change, labor and gender, in both historical and contemporary contexts. Her current research engages with 3D printing and Australian manufacturing.

\begin{abstract}
3D printing is not only a diverse set of developing technologies, it is also a social phenomenon operating within the political imaginary. The past half-decade has seen a surge of 'futuring' activity and widespread public attention devoted to 3D printing, which is typically represented as a harbinger of economic revival and political transformation. This article explores how 3D-printed futures are imagined across a broad political spectrum, by undertaking a multidisciplinary analysis of academic and popular literature. Three influential political imaginaries of 3D printing are identified: the maker-as-entrepreneur, the economic revival of the nation state, and commons-based utopias. In spite of stark contrasts in political alignment, these imagined futures share one important thing: an increasing awareness of design, making and production. This insertion of design into mainstream discourse is an important development for design history and theory, as it potentially enables an increasing public comprehension of the profound significance of design in the world, in both historical and contemporary terms.
\end{abstract}

\section{Keywords}

Additive manufacturing, 3D printing, political imaginary, futuring, manufacturing, makers, maker movement

\section{Introduction}

Additive manufacturing technologies (popularly known as 3D printing) have been available since the late 1970s, but it is only since the second decade of the twenty-first century that such technologies have entered mainstream awareness. Through a combination of media attention and increasing access to consumer-level technologies, 3D printing has recently prompted a great deal of 'futuring' activity, where it is often represented as a trigger for economic revival and political transformation. Mainstream journalism - fueled by understandably enthusiastic commentary from industry experts and academia - often features 
visions of localized production enabled by 3D printing. In these visions, offshored massmanufacturing factories may become an old-fashioned encumbrance, and the highly customized design and fabrication of consumable goods begins to occur in domestic, workshop and local retail contexts (see for example Gershenfeld 2005, 12; Richardson, Elliott and Haylock 2013, 142). Many of these visions present a future where the dominant way of making things goes through a profound shift, with major epistemological consequences for our understanding of design history, theory and practice.

Social scientist Thomas Birtchnell and 3D printing commentator William Hoyle have observed that "not since the days of the microprocessor and the computer 'chip' has a technology met with the degree of excitement that 3DP is attracting now" $(2014,2)$. We are told that with the flexibility and customizability of 3D printing, it is merely our imagination that will limit design possibilities (Lipson and Kurman 2013, 14; Mertz 2013, 12-14), and the practice of design will shift markedly (Bonanni et. al. 2008, 2553-62; Seepersad 2014, 1011; Atkinson 2010, 147). The enthusiasm about 3D printing extends well beyond design disciplines; fields as diverse as aerospace, medicine, and construction are said to be transforming at unprecedented rates (Baumers 2013; Bogue 2013, 309-10). Excitement builds about the ability to print human organs and food, and to print digitally programmable three-dimensional units (voxels) with the capacity to morph over time (Gershenfeld and Vasseur 2014, 60-2; Kostakis and Papachristou 2014, 436). Various makerspace and FabLab communities continue to bloom, and the ambitions that accompany these collective projects sometimes endow 3D printing (and other rapid manufacturing technologies) with powerful utopian capacities (Ehn, Nilsson, and Topgaard 2014; Walter-Herrmann and Büching 2013). Meanwhile, the list of printable materials continues to grow, and improved techniques for faster printing are regularly released. 
This article, however, sets aside technical breakthroughs and focuses on discourse. Here I consider 3D printing as a sociotechnical concept, often invoked as a catalyst for the next “industrial revolution” (see for example Lipson 2014, 61; Rifkin 2012; Anderson 2012; Berman 2012; Markillie 2012). ${ }^{1}$ The shape and nature of that revolution very much depends upon whom you ask. Accordingly, this article explores how 3D-printed futures are imagined across a broad political spectrum, by examining academic and journalistic literature related to 3D printing (with an emphasis on non-technical social and design content). I am concerned with the political and ideological entanglements that these emerging technologies are creating, with the (often utopian) worlds they prompt us to imagine, and the consequential implications for design knowledge and public understandings of design. In addressing these issues, this article draws connections between design and other disciplines, such as the social sciences and business discussions related to 3D printing. Here I build upon an emerging theory in media studies and the social sciences that 3D printing is, among other things, a conceptual and social phenomenon operating within the political imaginary (Fordyce 2015; Söderberg 2014).

Broadly speaking, the political imaginaries of technology are social phenomena arising from collective responses to perceived technological potential. In part, they imagine technology as constitutive of society and the economy. But the notion of the political imaginary is contested. Early concepts of the political and social imaginary focused on the collective beliefs and imaginary understandings that enable society to gel in relative harmony. For philosopher Cornelius Castoriadis, the social imaginary was a singular way that society saw, lived, and understood itself, made up of both symbolic and 'real' elements (1974). This imaginary had an institutional character, enabling it to represent and embody a given moral, social, or political order (Castoriadis 1974, 115-7; Bessant 2014, 34). Remembering this institutional character is worthwhile. It allows us to see how political imaginaries may be 
inserted into rhetoric as unquestioned social norms or "common sense". For example, one of the dominant political imaginaries of neoliberal culture is the linking of the term "innovation" explicitly with profit-making and entrepreneurialism. We will return to this issue in a later section.

Beyond Castoriadis, other analyses look to the role of future political imaginaries: these are multiple projections of possible futures that often involve the radical reimagining of social and political organization (Taylor 2003; Hage 2012). ${ }^{2}$ Philosopher Charles Taylor's conception of social imaginaries allows for pluralities; he speaks of 'multiple modernities' rather than a singular way to understand society. Drawing on Benedict Anderson's Imagined Communities (1991), Taylor defines the "social imaginary" as both "the ways people imagine their social existence" as well as the "deeper normative notions and images that underlie these expectations" $(2003,23)$. Such collective imaginings are "necessary fictions" and are, in themselves, causative of social and political change within a society (Nowotny 2014, 16). In that sense they are not merely "wafty" concepts; they have power and influence over broad social attitudes. In anthropologist Ghassan Hage's understanding of "radical political imaginaries", such visions of the future are prompted by a belief that society's problems are intractable and "total transformation" is the only answer $(2012,290)$. Radical political imaginaries can be collective or individual, and although frequently utopian, they tend to reflect broader historical circumstances, and thus inform us more about the present than they do about the future (Hage 2012, 291).

This article focuses on three distinct and influential political imaginaries emerging from 3D printing discourse:

\section{Maker-as-entrepreneur}

3D printing as an enabler for the individual maker as a neoliberal entrepreneur in a world of capitalist opportunity; 


\section{Economic revival of the nation state}

3D printing as a boon to productivity through the "onshoring" of manufacturing, enabling national economic revival, particularly in the Global North; and

\section{Commons-based utopia}

$3 \mathrm{D}$ printing as a social tool in a post-capitalist, commons-based utopia featuring material abundance, shared resources, and widespread community control over the means of production.

These three political imaginaries are some of the most influential narratives emerging from recent 3D printing discourse. It is important to acknowledge that not all writing about 3D printing features exaggerated or utopian themes; more measured discussions do exist. ${ }^{3}$ Furthermore, there are other political imaginaries that do not fit neatly within these three aforementioned categories. ${ }^{4}$ The visions described here, however, are highlighted because they repeatedly emerged as key themes in my analysis of 3D printing literature. These three political imaginaries are ubiquitous enough to have become important shapers of public attitudes to $3 \mathrm{D}$ printing technologies, and, by extension, the future of design.

This article first attends to a definitional framework for 3D printing that encompasses the concept of political imaginaries. It then critically examines the three aforementioned, dominant political imaginaries of 3D printing. The article concludes with a discussion section that considers how, in spite of the stark contrasts in political alignment, these three visions of 3D printing share one important thing: a growing public awareness of design and production. Herein lies the unforeseen benefit of these political imaginaries: the emerging public 'chatter' surrounding $3 \mathrm{D}$ printing is a productive development, as it potentially enables a growing understanding of the profound significance of design in the world, in both historical and contemporary terms. 
As the final part this article explains, this emerging public discourse has positioned design and making as central tenets of utopian political imaginings. This means that design is no longer considered a "fringe" or exclusive matter; it is increasingly understood to be central to social, political, and economic relations. Of course, particular design historians and design studies theorists have been making claims about the fundamental significance of design for some time (see for example: Dilnot 1982; Fry 2015, 4-6; Irwin 2015; Irwin, Kossoff, and Tonkinwise 2015). Design theorist Tony Fry has argued for "the huge complexity of the 'world-within-the-world' of human fabrication" as an "elemental force of futuring or defuturing consequence" $(2015,4)$. Similarly, proponents of "transition design" advocate for “design-led societal transition toward more sustainable futures" (Irwin 2015, 229). She argues that "more compelling future-oriented visions are needed to inform and inspire projects in the present and that the tools and methods of design can aid in the development of these visions" (Irwin 2015, 233). In other words, design is central to economic, social, and environmental transformation, and its ability to promote alternative visions is crucial for moving towards a sustainable future. The political imaginaries of 3D printing - while they might rest upon oversimplifications or exaggerated expectations - therefore offer the opportunity to clearly demonstrate this historical and contemporary centrality of design within the world. In order to understand what is at stake in these imagined futures, let us first attend to a definitional framework for this discussion.

\section{Defining Additive Manufacturing and 3D printing}

Additive manufacturing (AM) consists of a variety of emerging technological processes that use computer-aided designs (digital data) to fabricate objects through the additive layering of material. AM is one of several methods of rapid prototyping or rapid manufacturing (other methods include CNC machining, laser cutting, and 3D scanning). Various forms of AM have 
been available since the $1980 \mathrm{~s}$, using methods such as selective laser sintering (SLS), fused deposition modeling (FDM), stereolithography (STL), and more recently, continuous liquid interface production (CLIP) (Tumbleston et. al. 2015; Bourell et. al. 2009). ${ }^{5} \mathrm{AM}$ is part of a system of technologies that also encompass digital design (e.g. CAD files), feedstock (materials required to print matter, e.g. plastic spools) and associated digital and physical infrastructure (e.g. the Internet, hardware, energy, space) (Birtchnell and Hoyle 2014, 9).

The benefits of AM include that it enables easily customizable production, it does not require expensive re-tooling to change a design, it is ideal for prototyping, it is suitable for highly complex forms, and it offers great potential for globally-networked, collaborative digital design. The list of printable materials now includes metals, food, biomaterial, and textiles, and the cost of basic FDM printers is now "consumer-friendly". AM has stepped well beyond its original role as a good prototyping tool, and it is increasingly used in final production. It enables economic feasibility for bespoke and small-run manufacturing that lead to altered business approaches focusing more on manufacturing as a customized service, where the customer is increasingly involved in the design process (Petrick and Simpson 2013, 15; Walter-Herrmann and Büching 2013, 13).

If the above loosely sets up an understanding of AM and its advantages, then " $3 \mathrm{D}$ printing" is better understood as the social idea of additive manufacturing, in simplified and futuristic form (Fordyce 2015, 2-3). While the (usually) expensive, often slow, and cumbersome realities of today's SLS and FDM might not inspire broad participation just yet, it is the very idea of $3 \mathrm{D}$ printing that seems to prompt a great deal of futuring activity. The idea of 3D printing appears to neatly collapse the boundaries between designer, manufacturer, distributor, and consumer into one role, bringing irresistible immediacy to the prospect of bringing the virtual into the material world. Media scholar Robert Fordyce (2015) explored the distinction between the difficult realities and imagined capacities of $3 \mathrm{D}$ printing, using a 
concept of political imaginaries drawn from Hage (2012), among other frameworks. Fordyce focused on radical political imaginaries of 3D printing, specifically attitudes within far rightwing men's groups. In doing so he argued that the symbolic potential of 3D printing operates in a very different realm than the highly technical world of AM in practice (Fordyce 2015, 3). In other words, while AM consists of a diverse set of technological processes bound by everchanging limits and capacities, 3D printing is a social concept "that is not meaningfully limited by current technological or economic thresholds" (Fordyce 2015, 3). Because this dividing line is constantly shifting, the distinction it draws is perhaps more useful for design studies than previous divides, for example between industrial AM and consumer 3D printing (Birtchnell and Hoyle 2014, 39).

$3 \mathrm{D}$ printing is not the first set of technologies to be subject to enthusiastic political imaginings. As observed by sociologist Vincent Mosco: “It's striking how little predictions about technology have changed over the years." $(2004,1)$ In his analysis of the political myths surrounding the Internet and cyberspace in the early 2000s, Mosco warns that it is easy to dismiss imagined futures as fictional and speculative. But it is when technologies become commonplace, and therefore almost invisible (or, "black boxed"), that the real social and ideological changes can be felt. It is thus important to consciously observe their fictive power (Mosco 2004, 6). Social scientist Richard Barbrook likewise examined the "imaginary futures" inspired by the Internet in the 1990s and early 2000s, noting that "the Net was one of the 'tools for thought' which would liberate humanity from the Fordist factory society." $(2007,263)$

In this case, the potential afforded by $3 \mathrm{D}$ printing is a particularly attractive and "sticky" notion for germinating multiple political imaginaries. Importantly, these imaginaries situate technology as a significant intermediary, even a causative actor, in major social, political, and economic transformation. Often these political imaginings are unrealistic 
visions of a profoundly transformed way of living, where everything - wealth distribution, material ownership, social beliefs, skills, and lifestyle - is remade into an ideal state. 3D printing is appealing particularly because it is both scientific and design-based. The idea of 3D printing imbues production with seemingly magical, "Willy Wonka" ease. It seems to permit something to be created out of nothing (of course, designers and informed publics know this is not actually the case). 3D printing is closely tied to production, and, politics aside, it is generally agreed that control over production is key to any nation or society's economic viability (Birtchnell and Hoyle 2014, 9), regardless of the prevailing economic system.

The connection between $3 \mathrm{D}$ printing and economic politics is therefore closely aligned with ideals about individual, corporate, or national production, as it exists in an imagined sense. Design, making, and bringing things into being is at the core of production. Consequently, the political imaginary of 3D printing not only tells us about the values and prejudices of the present, it also shapes public understandings, for example, of design. Once design is implicated in both mainstream and radical political imaginaries, everyone has something at stake in the matter of designing and making. This shifts the questions of making and materiality well beyond the fields of design and engineering, into broader discourse. One result of this shift is the emergence of influential political imaginaries associated with 3D printing, as explored in the following sections.

\section{Political imaginary \#1: Maker-as-entrepreneur}

The "branded" version of the "Maker Movement" first emerged in the United States in 2005, with the inauguration of Make Magazine and the Maker Faire. The "maker" identity was well established by 2009 (Tocchetti 2012), and popularized in Mark Hatch's widely distributed Maker Movement Manifesto (2013). ${ }^{6}$ Techno-utopianism is often linked closely with faith in 
the market, and with the possibility of growing rich (Bastani 2012; Mosco 2004, 4). The vision of $3 \mathrm{D}$ printing as a wealth enabler is seductively simple: a creative tinkerer - utilizing a combination of $3 \mathrm{D}$ printing machinery, $\mathrm{CAD}$ technologies, open-source software, global internet distribution, and crowdfunding (e.g. Kickstarter, Pozible) - is able to bypass the restrictions of mass-manufacturing, and launch themselves into the market as a neoliberal innovator, an heroic individual: the next Steve Jobs or Mark Zuckerberg.

However, there is a broad variety of "makers" associated with 3D printing, many of whom do not fit the "maker-as-entrepreneur" identity. There are those who work collectively, sharing designs online (on sites such as Thingiverse) and using communally-owned tools within a workshop. There are those with no plans to commercialize or sell their designs, who design and produce bespoke objects simply because they are passionate about making and DIY (Beegan and Atkinson 2008; Jackson 2010). There are those who make out of economic necessity. Some makers sustain very small-scale craft businesses, with no desire to expand beyond boutiques or small online businesses hosted by e-commerce platforms like Etsy. While often ignored as a "dying” group, waged labor makers still exist, even in the Global North (Gibson, Carr and Warren 2015). Some of these makers also exercise their skills and making activities outside of their contractual employment (Stein 2015; 2016). Other makers tie their activities to a politics of resistance to corporate culture and exploitative manufacturing supply chains (Vanni 2015). Then there are entrepreneurial makers, who dream they will one day invent something that will catapult them into commercial success, enabling a start-up company to explode into global prominence. Although not all makers are cut from this latter mold - and arguably few really are - it is this final vision of the maker-asentrepreneur that has been tremendously influential in mainstream media visions connected to the potential of $3 \mathrm{D}$ printing. 
Bre Pettis, co-founder and CEO of the 3D printing company MakerBot Industries, followed this trajectory. [Figure 1] His began his career as an artist, teacher, and video blogger, before co-founding a start-up and becoming CEO of a successful, consumeroriented, 3D printing company. Significantly, MakerBot Industries is now owned by Stratasys, one of the largest corporate players in 3D printing. In 2012 Makerbot infamously withdrew open-source access to the design of its products, prompting outrage from maker and peer-production communities (Söderberg 2014, 4). The tensions arising from Pettis' shift away from the maker fringes into the corporate world were widely reported (e.g. Brown 2012), but what is most interesting is the way in which Pettis' trajectory fits the dominant, and apparently desirable, political imaginary of the maker-as-entrepreneur. ${ }^{7}$

The most clear-cut example of this political imaginary can be found in Chris Anderson's popular book Makers: The New Industrial Revolution (2012). Former editor of Wired and founder of the company 3D Robotics, Anderson's take on the potential of 3D printing has shaped public understandings of "makers". Prominent 3D printing commentators such as Cory Doctorow and Neil Gershenfeld have noted Anderson's influence on their thinking (Boussard 2014, 256). Anderson claims that emerging AM, Internet distribution, crowdfunding and open-source sharing are significant enablers of a new kind of maker (2012). No longer will inventors remain frustrated and unrecognized for their creations: if they capitalize upon available technological and communications resources (e.g. Thingiverse), they will be able to launch successful entrepreneurial endeavors. Anderson writes that, "the history of the past two decades online is one of an extraordinary explosion of innovation and entrepreneurship. It's now time to apply that to the real world with far great [sic] consequences ...Welcome to the New Industrial Revolution." $(2012,15-6)$ In this political imaginary the world is filled with opportunity and profits to be reaped, and the economic landscape nurtures and rewards those who are truly "innovative". 
The maker-as-entrepreneur is a relentlessly positive vision, where little is said about those who do not have the material or social capital (not to mention the desire) to succeed in this manner. It treats humanity as a collection of mobile individuals with equal access to opportunity, and freedom to exercise their ability to earn a profit, should they wish to do so. Implicitly, innovation is narrowly defined as an exercise that specifically results in commercial success. Little is acknowledged of the risks associated with open-source and shared knowledge, that is, that free labor can be exploited easily and ideas swiftly commandeered by large corporate players (Beverungen, Bohm and Land 2015). The key problem with this vision is that it will benefit only the lucky few, who are most likely already relatively privileged individuals (and there's a good chance that they are white and male) (Tocchetti 2012, 8). It is a political imaginary that elides the concepts of flexibility and freemarket capitalism with the idea of democracy.

Despite briefly acknowledging the problems of the late-capitalist economy, such as rising unemployment and economic recession, Anderson nonetheless calls for an intensification of capital-led activities $(2012,15)$. According to him, more entrepreneurialism will bring the Global North out of a slump (Anderson 2012, 16). Sociologists Luc Boltanski and Eve Chiapello (2005) have critiqued a similar problem in broader social and political thinking. They note that notwithstanding booming markets from the late twentieth century onwards, mainstream economists and politicians were surprised to find that poverty and inequality were on the rise, and yet the same observers did not think to question the broader systemic and political contexts that brought this state of affairs into being (Boltanski and Chiapello 2005, xii).

While measured and sensible warnings about 3D printing are less common, technology critic Yvgegny Morozov stands out in his questioning of the ambitions of the maker movement (2014). Drawing on historical precedents in the late nineteenth century British 
Arts and Crafts Movement, and Stuart Brand's DIY techno-utopianism proposed in the 1960s and 1970s, Morozov critiques the Maker Movement's lack of grounding in political principles and practical realities. He notes that - like Brand's followers who were encouraged to believe that owning a personal computer in the 1970 s was akin to being a political radical - the consumption of maker technologies could have a similarly tenuous relationship to realworld political transformation. Morozov parallels the Maker Movement with the Arts and Crafts movement, observing that they feature the same "reluctance to talk about institutions and political change", which reduces the spirit of genuine labor reform into "consumerism and DIY tinkering" (2014). Similarly, sociologist Sara Tocchetti notes that this "branded" maker identity has an historical lineage in the myth of "grassroots American innovation" as a source of entrepreneurial success $(2012,1)$. This places making squarely in the realm of a conservative American vision of a self-sufficient, middle-class individual, who may believe themselves to be part of a counter-cultural movement, and yet implicitly situates their activities within a mainstream culture of entrepreneurialism (Tocchetti 2012, 3).

In this political imaginary, design exists as a means to create merely a marketable product, rather than a deeper understanding of design as potentially socially transformative, and as a fully implicated element within social, political, and economic spheres. Anderson goes so far as to claim that, with these new distributed making technologies, "we are all designers now" $(2012,53)$. Design theorist Andrew Jackson has critiqued Anderson's claims on this front, observing that such a claim "fails to recognize the complexity of the design process and the iterative nature of product development" $(2014,312)$. Designers and engineers will likely scoff at the simplistic claim that "we are all designers now", but the important point is that Anderson's political imaginary has influence, and it speaks a narrow language of "innovation" that has recently been taken up by policy makers and governments (Dodgson 2015). 


\section{Political imaginary \#2: Economic revival of the nation state}

The most dominant political imaginary of 3D printing is the liberal democratic imaginary, characterized by notions that privilege profit over other concerns, but also value the stability and economic viability of the nation state (Fordyce 2015, 5). In this political imaginary, 3D printing is envisaged as a major player in national-scale economic revival. Advanced manufacturing technologies such as $3 \mathrm{D}$ printing theoretically enable nations to become specialists in high-end products, offering customized design, small economies of scale, and localized production, all without the need to compete with mass-manufacturing giants such as China and India. This future vision is particularly prevalent in relation to the idea of "onshoring" manufacturing back to the Global North, but it is also a feature of developments in the Global South. ${ }^{8}$

In a much-cited article from 2012, The Economist's Paul Markillie triumphantly hailed the commencement of a "third industrial revolution", where "offshore production is increasingly moving back to rich countries" (2012). In the same year, the European Commission called for a new "industrial revolution" to rise in Europe, one that would capitalize upon new and emerging technologies, bringing production back on-shore $(2012,1-$ 3). Business analyst Richard D'Aveni proclaimed that 3D printing “will change again how the world leans", and that "China will have to give up on being the mass-manufacturing powerhouse of the world" $(2013,34)$. In a similar vein, economic theorist Jeremy Rifkin has called for a "bold new economic narrative", with a future vision combining green energy, social networks, Internet communications, and maker technologies (2011). While Rifkin acknowledges that this will requires the "mass retraining of workers" into a "new high-tech workforce", he is optimistic that in this new era "everyone can potentially be their own manufacturer" in a localized, distributed form of on-shore manufacturing (2012). 
Small but relatively wealthy countries, such as Australia and New Zealand, have regularly featured calls to capitalize on emerging 3D printing technologies, with some commentators noting the advantages 3D printing brings for customization and high-tech specialization. For example, business analysts Julie Kim and David Robb suggest that 3D printing "could be the key to a new world of niche markets for New Zealand companies" (2014, 16). Likewise, Australian designers, business commentators, and scientists have enthused about the possibility of 3D printing as an industry savior for Australia's flagging manufacturing industry (see for example Barnes 2013; Richardson and Haylock 2012). Other commentators resist the temptation to label single technologies as national industry saviors, focusing more on design thinking and "design-led innovation" as strategies for local renewal in manufacturing (Bucolo 2014). But again, design is given a central role in the revitalization of a nation's productivity. The question of how things are designed, produced, and distributed has become a mainstream conversation, rather than being perceived as a niche area.

While these imaginaries deserve a healthy dose of cynicism, the situation offers great potential for broadening public awareness of the role of design as deeply imbricated within social and economic transformation. Like the maker-as-entrepreneur vision, the "economic revival of the nation state" imaginary tends to be optimistic, specifically tying $3 \mathrm{D}$ printing to predictions of economic growth and to the concept of innovation. Notably, the vision of booming, high-tech national economies provides no real solutions to the issue of unemployment (following deindustrialization) in the Global North nor in the Global South (the latter of which could, at least in this framework, experience a decrease in global supplychain demand). ${ }^{9}$ Political statements in this context often feature calls for a return to a "country that makes things" (see for example Owens 2016), but this rhetoric tends to avoid the difficult question of how AM (and indeed robotics) tend not to require large workforces, and the profits are not guaranteed to stay "onshore". ${ }^{10}$ 


\section{Political imaginary \#3: Commons-based utopia}

Some optimistic future visions of 3D printing are not centered on capital, instead emphasizing "solving problems at a collective human level” (Rundle 2014, 192). In these alternative utopian visions, the "revolution" triggered by 3D printing is not merely an economic one, but one that could constitute a complete transformation of social and economic relations. There is a discernible emphasis on open-design and commons-based material production - an extension of ideas that were already prevalent in open-source software communities prior to the widespread popularity of 3D printing (Marttilla, Nilsson and Seravalli 2014, 87). Sociologist of science and technology Mike Michael has argued that the opening up of access to technologies that manipulate plastic "and their co-constitutive discourses" constitutes a "democratization" of plastic $(2013,30)$. Some of these future visions involve various forms of a commoning where the ownership of the means of production is democratized, and self-sufficient community productivity is enabled through a resourceful combination of self-replicating printers and peer-networked sharing, with little or no dependency on large corporate suppliers. Some envisage communities that are almost entirely free from commerce, returning material goods to a pre-modern barter system in which 3D printers operate as modified open-source tools for recycling and upcycling objects (De Filippi and Troxler 2013, 74; Walter-Herrmann 2013, 36).

The utopian politics of 3D printing is not easily categorized along left or right political lines (Rundle 2014, 56). It is part-libertarian, part-anarchist, part-socialist, and partcommunitarian. Kevin Harrington, founder of Neuron Robotics, has explained that, "What we are talking about is a total self-producing environment that draws on its own recycled material, prints out its own energy sources, and is connected to food production at one end, and system production at the other." (Rundle 2014, 54) Knowledge is shared openly in peer- 
to-peer networks, and design and making is undertaken collaboratively across digital networks and in makerspaces and FabLabs. [Figure 2] Communities focus on sharing DIY skills, and technologies and tools are likewise collectively owned. Self-replicating 3D printers and materials-recycling eliminates dependence on larger corporate suppliers. Energy is produced from local, renewable sources, facilitated in part by 3D printed technologies. Gradually, people find that their material needs can be met by their community situations, and they opt to leave waged labor (if they could ever find it in the first place). In this political imaginary, once production is quietly liberated from the powerful few and redistributed among the hands of the many, capitalism will eventually "suffer a fatal crisis of value" and another system (some suggest socialism) will "bring humanity to the next stage" (Rundle 2014, 197).

One of the best-known political imaginaries along these lines is a vision of a society that maintains "wealth without money": a situation engineered in part by the use of selfreplicating $3 \mathrm{D}$ printers. The most renowned protagonist associated with this position is Adrian Bowyer, a retired mechanical engineer who developed the RepRap project, the first 3D printer that can self-replicate (i.e. print itself). [Figure 3] In the RepRap vision, global supply chains are profoundly disrupted as local citizens discover they can print their own open-source $3 \mathrm{D}$ printers without dealing with a corporate supplier. ${ }^{11}$ In theory, the RepRap returns the entire control of production into the hands of the "masses". This achieves an essentially Marxist goal "without all that messy and dangerous revolution stuff" (Bowyer 2011 [2004]). According to Boyer, such a system could, ideally, produce "wealth with a minimal need for industrial manufacturing", and the number of printers in existence (and thus the wealth they produce) could "grow exponentially" (2011 [2004]).

This alternative political imaginary of 3D printing recalls Herbert Marcuse's technological utopianism (1941 [1998]), and economist E.F. Schumacher's polemical vision 
Small is Beautiful (1974). Both these visions called for a "technology with a human face" (Schumacher 1974, 123), bringing humanity out of the cycles of war, poverty, crippling labor relations, and environmental destruction. In these various techno-utopias, mechanization has the capacity to free people from the drudgery of manual labor, and the resulting material abundance is fairly shared throughout society (Marcuse 1941 [1998], 63-4). Individuals freed from the "burden" of work have time to their own pursuits and "develop [their] potential" (Schumacher 1974, 123).

This all sounds wonderful, however most commentators (including the RepRap team) fall short of identifying any viable political method by which this transition could actually occur within liberal capitalism. In fact, notwithstanding the rhetoric and hype, the actual stated "goals" of the RepRap project involve less structural economic change:

The self-replicating nature of RepRap could also facilitate its viral dissemination and may well facilitate a major paradigm shift in the design and manufacture of consumer products from one of factory production of patented products to one of personal production of un-patented products with open specifications. (Bowyer 2011 [2004]) As this quote demonstrates, the RepRap team specifically envisages design - and not revolutionary politics - as a site of realizable change: an evolution from mass-manufactured, factory-produced goods to a widespread practice of personal, customized production. If viewed in relation to design history, the ontological and historiographical implications of such a shift are potentially groundbreaking, as will be discussed in the following section.

Notwithstanding the RepRap team's reticence to sketch out a specific politics, others have leapt on the idea of self-replicating 3D printers as the key to overturning capitalism. Sociologist Jakob Rigi argues that peer-production - collaborative production undertaken with openly shared materials, tools, and IP - is "similar to what Marx described as advanced capitalism" $(2013,402)$. It does not involve a monetary exchange, and it operates in a "decentered network" where the "division of labor is transcended and replaced" (Rigi 2013, 402-3). While Rigi acknowledges that peer-production currently constitutes "small islands" 
within a capitalist system, he maintains that the peer-production of material items could potentially replace capitalism entirely, or at least that 3D printing could "bring the capitalist system to a decisive crisis" $(2013,411)$.

This vision of a utopian, commons-based society is also articulated in counter-cultural and design fields (typically with less Marxist theory than Rigi applies). Radical labor historian Chris Carlsson envisages a liberated politics of work, where people are freed from waged labor, and can involve themselves in productive activities of their own choosing (e.g. making, growing, fixing) (2008). Like Rigi, Neil Gershenfeld (MIT Director of the Center for Bits and Atoms) speaks of the democratization of the ownership of the means of production via access to openly shared tools and designs in places such as FabLabs $(2005,21)$. His political position is less confrontational than Carlsson's or Rigi's. Gershenfeld's rhetoric harkens back to a pre-industrial ideal of craft and artisanal production $(2005,8)$. He is hopeful that "openness will ultimately triumph" over the control sought by corporate capital, perhaps unconvincingly citing the Internet as an example where free-access, sharing, and decentralized design has won out over proprietary systems (Gershenfeld and Vasseur 2014, 60). Socio-technical analyst Peter Troxler also engages with the notion of a new peerproduction commons that could revolutionize the current economic system $(2010 ; 2013$; Troxler and De Filippi 2013). He acknowledges that "the route to this new world of open source hardware and distributed manufacturing might be somewhat thornier than in software" (Troxler 2013, 183-4), and that the power structures in place may act to prevent the "lateral" relationships needed to achieve such a transformation (Troxler and van Woensel 2013, 188).

This question of power relations points to a major unresolved tension within the utopian politics of those who advocate for commons-based material production. It involves the problem of unpaid or free labor, and the ease of its exploitation by those who might prey on digital sharing platforms such as Thingiverse. Technology giants such as Facebook and 
Google have already built their business-models from the profits enabled by freely shared, user-added content (Beverungen, Bohm and Land 2015). Many warn that if these conditions continue, the free labor of 3D printing users (such as those sharing their open-source digital designs) will simply be absorbed by dominant industry players (Lanier 2014; Marttila, Nilsson and Seravalli 2014). On the other hand, there are those in the 3D printing community who value freely-shared designs and technologies and the skills-sharing that this enables, as open access allows projects such as RepRap to spread, exponentially increasing the number of people independently producing 3D printers without the assistance of a corporation (Söderberg 2013).

\section{Discussion: Repositioning Design and Making in Sociopolitical Discourse}

As noted in the Introduction, proponents of "transition design" have recently argued that "visions" of the future (or "design futuring") are essential in order to pave the way for design's vital role in a sustainable and ethically responsible future (Irwin 2015, 233; Dunne and Raby 2013, 2-3). This article has identified three strands of such "visions", which exist both within and beyond design. While I have identified some of their limitations as political imaginaries, their existence is nonetheless significant. This is because the real and imagined capacity of 3D printing has catapulted design into mainstream understandings of the world. Suddenly politicians, business executives, and journalists are talking about making and manufacturing, with great hope and optimism for future jobs and prosperity. ${ }^{12}$ [Figure 4]

While the statements made in commercial media might sometimes fuel unrealistic expectations, this level of public interest could be tremendously useful for designers, design theorists, and design historians alike. This is because 3D printing's ability to excite the public imagination allows us to understand the significance of design in relation to the worlds that we make. This is in sharp distinction to previous public understandings of post-Fordist 
manufacturing, where products tended to be made out of sight, usually in mass-production contexts, and design occurred mysteriously in an exclusive, professionalized realm (Birtchnell and Urry 2012, 390).

The emerging discourse associated with 3D printing presents fundamental challenges to our understanding of how objects are brought into being, and by whom. It offers, for example, a possible way to transcend the global corporate system of off-shored massmanufacturing in the Global South, where (often) poorly-made products are produced under exploitative labor conditions. In theory, manufacturing could be brought back - not just "onshore" - but into local communities and homes, potentially enabling a level of control of production that harkens back to pre-industrial craft and cottage-industry activity (Richardson, Elliott and Haylock 2013; Atkinson 2010, 145; Gershenfeld 2007).

Furthermore, this increased awareness of design and making also bodes well for a more responsive and informed understanding of materials: where they come from, how to use them, and how to transform them in cycles of use. Indeed, recent work suggests that "the importance of materials in the social imagination" rises and falls throughout history, and that materials themselves "demand special attention at the current social moment in history" (Drazin 2015, 3). Material culture analyst Susanne Küchler has noted that, as the distinction between production and consumption "gives way to a socially informed material production via the co-creation of commodities with consumers", it is not only production that must be watched closely, but also materials, which can be influential in sociotechnical change (2015, 267).

The three political imaginaries examined here all sidestep the rather complex problems of volatile materials production and access to diverse raw materials. In reality it is likely that a 3D-printed dishwasher, for example, would be logistically complex on a local scale, and dangerous to produce domestically (Majewski 2014). Such ideas also ignore the 
dominance and subsuming capacity that large corporate players can exert over smaller industries and local communities, in relation to both labor and affordable access to technologies. Nonetheless, the important point for this article is the fact that making, supply chains, and mass-manufacturing are being publicly discussed at all. That they are receiving such attention represents a meaningful shift in a promising direction: mainstream awareness of the nature of design and production is on the rise.

What are the implications for design history and theory? The idea of printing your own, fully-customized appliances, clothing, tools, and furniture has obvious appeal. If this were to actually come about, it would signify an extraordinary historical rupture for the way we understand design and chart design history. The very notion of who (or what) a designer is could be called into question, raising provocative questions about authorship, design quality, design education, and the very definition of 'design' as both a noun and a verb.

But the challenges facing design history run deeper than that. Returning to Fry, a key problem for design and design historians is a broad public inability to recognize that it is impossible to "comprehend the worlds of human existence without design, its agency, function and presence" $(2015,6)$. Without this understanding, design history remains a thematically impoverished, specialist discipline based in connoisseurship and without strong links to significant sociopolitical analysis. The great symbolic potential of $3 \mathrm{D}$ printing is that it can bring this designed world of which Fry speaks into sharp relief and, with that, trigger a broader sense of social responsibility for the literal shaping of that world. 3D printing therefore needs to be understood as much more than a "tool". It is a mutually constitutive system within and beyond design. 3D printing shapes us as much as we shape it. And it also exists as an ideological concept as well as a technological system.

When faced with an exciting and apparently "new" technology, it can be easy to forget some fundamental principles (which can be applied to design theory and beyond). It is 
easy to forget to ask: In whose interests will these technologies operate? What kind of world are we bringing into being? If there is to be a "revolution", what might it look like? No one can agree on what a third industrial revolution will involve, although many have speculated, as this article attests. Maintaining an awareness of these divergent political visions of the future can help us understand the ideological power of the imagined designed world. 3D printing's theoretical ability to return production to the hands of 'the people' may produce some idealistic visions, but it may also engender widespread awareness of the designed nature of the entire world around us - design's “expanded field” (Tonkinwise 2014) prompting further questioning and the will to improve upon the status quo. The future potential of localized or domestic-level manufacturing may not end up being as logisticallyfeasible or impressive as some commentators suggest, but this speculative potential alone may help unlock the "black box" of global mass-manufacturing and supply chains. It brings the question of how things are made (and by whom, and where) into the center of popular, mediatized public concerns.

It is my hope that this article can open up the field for further critical discussion regarding $3 \mathrm{D}$ printing in design history and design studies. The discourse must move beyond technical and practice-based analysis to incorporate discussions that encompass philosophical, historical, and political arenas. To some extent, all this excitement about the future is warranted. It is clear that $3 \mathrm{D}$ printing technologies legitimately have the potential to transform sociotechnical relations of design, production, employment, distribution, and consumption, but it will likely impact some industries more than others (Petrick and Simpson 2013; Ratto and Ree 2012, 1; Birtchnell and Urry 2016, 2012). However the lack of current empirical studies - and the fact that these technologies are in an emerging, embryonic mode means that existing discourse tends to operate in a predictive manner (Ratto and Ree 2012, 6). There is a need for more qualitative and quantitative studies of $3 \mathrm{D}$ printing as these 
technologies become more widespread. We also need to think much more carefully about the role that $3 \mathrm{D}$ printing is beginning to exert as a conceptual driver of social thought about design and making. In this respect, this article is merely the beginning of what I hope can become an extended conversation. The time is ripe to take stock of the powerful ideological background that underpins attitudes to 3D printing.

\section{References}

Anderson, Benedict. 1991. Imagined Communities: Reflections on the Origin and Spread of Nationalism. New York; London: Verso.

Anderson, Chris. 2012. Makers: The New Industrial Revolution. New York: Crown Publishing.

Arieff, Allison. 2014. "Yes We Can. But Should We? The Unintended Consequences of the Maker Movement." reForm in Medium, September 15. Accessed November 27, 2016. https://medium.com/re-form/just-because-you-can-doesnt-mean-you-should$252 \mathrm{fdbcf76c8.}$.

Atkinson, Paul. 2010. "Boundaries? What Boundaries? The Crisis of Design in a PostProfessional Era." The Design Journal 13 (2): 137-55.

Barbrook, Richard. 2007. Imaginary Futures: From Thinking Machines to the Global Village. London: Pluto Press.

Barnes, John. 2013. "Can 3D Printing Rebuild Manufacturing in Australia?" The

Conversation, October 7. Accessed November 27, 2016. http://theconversation.com/can3d-printing-rebuild-manufacturing-in-australia-16670.

Bastani, Aaron. 2012. "The Third Industrial Revolution - a Response to the Economist." openEconomy, April 26. Accessed November 27, 2016.

www.opendemocracy.net/openeconomy/aaron-peters/third-industrial-revolutionresponse-to-economist.

Baumers, Martin. 2013. "3D Printing Market Is Booming as the Buzz Catches on." The Conversation, August 29. Accessed November 27, 2016. http://theconversation.com/3dprinting-market-is-booming-as-the-buzz-catches-on-17602.

Beegan, Gerry, and Paul Atkinson. 2008. "Professionalism, Amateurism and the Boundaries of Design.” Journal of Design History 21 (4): 305-13.

Berman, Barry. 2012. "3-D Printing: The New Industrial Revolution.” Business Horizons 55: $155-62$.

Bessant, Judith. 2014. "The Political in the Age of the Digital: Propositions for Empirical Investigation." Politics 34 (1): 33-44.

Beverungen, Armin, Bohm, Steffen, and Land, Chris. 2015. "Free Labour, Social Media, Management: Challenging Marxist Organization Studies." Organization Studies 36 (4): 473-89.

Birtchnell, Thomas, and William Hoyle. 2014. 3D Printing for Development in the Global South. London; New York: Palgrave Macmillan. 
and Urry, John. 2016. A New Industrial Future? 3D Printing and the Reconfiguring

of Production, Distribution, and Consumption. London; New York: Routledge.

- and Urry, John. 2013. "3D, SF and the Future." Futures 50: 25-34.

- and Urry, John. 2012. "Fabricating Futures and the Movement of Objects."

Mobilities 8 (3): 388-405.

Bogue, Robert. 2013. “3D Printing: The Dawn of a New Era in Manufacturing?” Assembly Automation 33(4): 307-11.

Boltanski, Luc, and Eve Chiapello. 2005. The New Spirit of Capitalism. Trans. Gregory

Elliott. New York; London: Verso.

Bonanni, Leonardo, Amanda Parkes, and Hiroshi Ishii. 2008. "Future Craft: How Digital

Media Is Transforming Product Design." Conference proceedings, CHI-2008. Florence.

Bourell, David L., Joseph J. Beaman, Ming C. Leu, and David W. Rosen. 2009. "A Brief

History of Additive Manufacturing and the 2009 Roadmap for Additive Manufacturing:

Looking Back and Looking Ahead." Conference proceedings, RapidTech: US-TURKEY

Workshop on Rapid Technologies. Accessed November 27, 2016.

http://iweb.tntech.edu/rrpl/rapidtech2009/bourell.pdf.

Boussard, Justine. 2014. "Book Review: Makers: The New Industrial Revolution and The

New Industrial Revolution: Consumers, Globalization and the End of Mass Production."

Design and Culture 6 (2): 255-58.

Bowyer, Adrian. 2011 [2004]. "Wealth Without Money." RepRap Wiki. Accessed November 27, 2016. http://reprap.org/wiki/Wealth_Without_Money.

Brown, Rich. 2012. "Pulling Back from Open Source Hardware, MakerBot Angers Some

Adherents." cNet, September 27. Accessed November 27, 2016.

www.cnet.com/au/news/pulling-back-from-open-source-hardware-makerbot-angerssome-adherents/.

Bucolo, Sam. 2014. "Design Led Innovation - Underpinning a Future Manufacturing

Workforce." Conference proceedings, Manufacturing in 2030 - The New Horizon.

Sydney.

Carlsson, Chris. 2008. Nowtopia: How Pirate Programmers, Outlaw Bicyclists, and Vacant-

Lot Gardeners Are Inventing the Future Today. San Francisco: AK Press.

Castoriadis, Cornelius. 1987. The Imaginary Institution of Society. Cambridge: Polity Press.

D'Aveni, Richard A. 2013. "3D Printing Will Change the World." Harvard Business Review

(March): 34.

Daly, Angela. 2016. Socio-Legal Aspects of the 3D Printing Revolution. London: Palgrave

MacMillan.

De Filippi, Primavera, and Peter Troxler. 2013. "From Material Scarcity to Artificial

Abundance - The Case of FabLabs and 3D Printing Technologies." Conference

proceedings, 3D Printing: Destiny, Doom or Dream? Leiden.

Dilnot, Clive. 1982. "Design as a socially significant activity: an introduction." Design

Studies 3 (3): 139-46.

Doctorow, Cory. 2009. Makers. London: Harper Collins.

Dodgson, Mark. 2015. "The Government's Focus on Innovation Is Too Narrow." The

Conversation, September 29. Accessed November 27, 2016.

$\mathrm{https}$ ://theconversation.com/the-governments-focus-on-innovation-is-too-narrow-48178.

Drazin, Adam, and Susan Küchler (eds). 2015. The Social Life of Materials: Studies in

Materials and Society. London, New Delhi, New York; Sydney: Bloomsbury.

Dunne, Anthony and Fiona Raby. 2013. Speculative Everything: Design, Fiction, and Social

Dreaming. Cambridge, MA: MIT Press.

Ehn, Pelle, Elisabet M. Nilsson, and Richard Topgaard (eds). 2014. Making Futures:

Marginal Notes on Innovation, Design and Democracy. Cambridge, Mass.: MIT Press. 
Fordyce, Robert. 2015. "Manufacturing Imaginaries: Neo-Nazis, Men's Rights Activists and 3D Printing." Journal of Peer Production 6: 1-9.

Fry, Tony. 2015. "Whither Design / Whether History." In Fry, Tony, Dilnot, Clive and Stuart, Susan (eds), Design and the Question of History, 1-130. London, New Delhi, New York; Sydney: Bloomsbury.

Gershenfeld, Neil. 2005. Fab: The Coming Revolution on Your Desktop: From Personal Computers to Personal Fabrication. New York: Basic Books.

- 2012. "How to Make Almost Anything: The Digital Fabrication Revolution."

Foreign Affairs 91 (6): 43-57.

—. and J.P. Vasseur. 2014. “As Objects Go Online.” Foreign Affairs 93 (2): 60-7.

Gibson, Chris, Chantel Carr, and Andrew Warren. 2015. "Making Things: Beyond the Binary of Manufacturing and Creativity." In Kate Oakley and Justin O'Connor (eds), Routledge Companion to the Cultural Industries, 86-96. London; New York: Routledge.

- 2012. "A Country that Makes Things?” Australian Geographer 43(2): 109-13.

Hage, Ghassan. 2012. "Critical Anthropological Thought and the Radical Political Imaginary Today." Critique of Anthropology 32 (3): 285-308.

Hatch, Mark. 2013. The Maker Movement Manifesto: Rules for Innovation in the New World of Crafters, Hackers, and Tinkerers. United States: McGraw Hill Publishing.

Heemsbergen, Luke. 2014. "What Price our Fascination with Cheaper 3D Printing?" The Conversation, January 20. Accessed November 27, 2016.

http://theconversation.com/what-price-our-fascination-with-cheaper-3d-printing-22007.

_., Robbie Fordyce, Tom Apperley, Mike Arnold, Thomas Birtchnell, and Bjorn Nansen. 2016. 3D Printing Civic Practices and Regulatory Challenges. Melbourne Networked Society Institute, Research Paper 2-2016. Melbourne.

Irwin, Terry. 2015. "Transition Design: A Proposal for a New Area of Design Practice, Study, and Research." Design and Culture 7 (2): 229-46.

Jackson, Andrew. 2014. "Book Review: Makers: The New Industrial Revolution." Journal of Design History 27 (3): 311-2.

- 2010. "Constructing at Home: Understanding the Experience of the Amateur Maker." Design and Culture 2 (1): 5-26.

Kim, Julie, and David Robb. 2014. "3D Printing: A Revolution in the Making." University of Auckland Business Review 17 (1): 16-25.

Kostakis, Vasilis, and Marios Papachristou. 2014. "Commons-Based Peer Production and Digital Fabrication: The Case of a RepRap-Based, Lego-Built 3D Printing-Milling Machine." Telematics \& Informatics 31: 434-43.

Lanier, Jaron. 2014. Who Owns the Future? New York, London; Toronto: Simon \& Schuster. Lipson, Hod. 2014, "Is Additive Manufacturing a Real Revolution?," 3D Printing and Additive Manufacturing 1(2): 61.

- and Melba Kurman. 2013. Fabricated: The New World of 3D Printing, John Wiley \& Sons, Indianapolis.

Macnaghten, Phil., and Julia S. Guivant. 2011. "Converging Citizens? Nanotechnology and the Political Imaginary of Public Engagement in Brazil and the United Kingdom." Public Understanding of Science 20 (2): 207-20.

Majewski, Candice. 2014. "3D Printing Possibilities Are Beautiful but Not Limitless." The Conversation, April 28. Accessed November 27, 2016. http://theconversation.com/3dprinting-possibilities-are-beautiful-but-not-limitless-25890.

Marcuse, Herbert. 1998 [1941]. Technology, War and Fascism: Collected Papers of Herbert Marcuse Volume One. London: Routledge.

Markillie, Paul. 2012. “A Third Industrial Revolution.” The Economist, April. Accessed November 27, 2016. www.economist.com/node/21553017. 
Marttila, Sanna, Elisabet M. Nilsson, and Anna Seravalli. 2014. "Opening Production: Design and Commons." In Making Futures, 87-97.

Mertz, Leslie. 2013. "New World of 3-D Printing Offers 'Completely New Ways of Thinking." IEEE Pulse 4 (6): 12-4.

Michael, Mike. 2013. "Process and Plasticity: Printing, Prototyping and the Prospects of Plastic." In Jennifer Gabrys, Gay Hawkins, and Mike Michael (eds), Accumulation: The Material Politics of Plastic, 30-46. London: Routledge.

Morozov, Evgeny. 2014. "Making It: Pick up a Spot Welder and Join the Revolution." The New Yorker, January 13. Accessed November 27, 2016. www.newyorker.com/magazine/2014/01/13/making-it-2.

Mosco, Vincent. 2004. The Digital Sublime: Myth, Power, and Cyberspace. Cambridge Mass.; London: MIT Press.

Neely, Erica J. 2014. "The Risks of Revolution: Ethical Dilemmas in 3D Printing." Conference proceedings, CEPE/ETHICOMP Joint Meeting, Les Cordeliers, France.

Nowotny, Helga. 2014. "Engaging with the Political Imaginaries of Science: Near Misses and Future Targets." Public Understanding of Science 23 (1): 16-20.

Owens, Jared. 2016. "Federal Election 2016: ALP's \$59m to Make Things Other Than Cars." The Australian, May 17. Accessed November 27, 2016. www.theaustralian.com.au/federal-election-2016/federal-election-2016-alps-59m-tomake-things-other-than-cars/news-story/a43f5a17a7d1ecb1ae07845fb98c405e.

Petrick, Irene J., and Timothy W. Simpson. 2013. "3D Printing Disrupts Manufacturing: How Economies of One Create New Rules of Competition." Research Technology Management 56 (6): 12-6.

Ratto, Matt and Robert Ree. 2012. "Materializing Information: 3D Printing and Social Change." First Monday 17 (7). Accessed November 27, 2016. http://firstmonday.org/ojs/index.php/fm/article/view/3968/3273.

Record, Isaac, Ginger Coons, Daniel Southwick, and Matt Ratto. 2015, "Regulating the Liberator: Prospects for the Regulation of 3D Printing." Journal of Peer Production 6: $1-12$.

Richardson, Mark, Susie Elliott, and Bradley Haylock. 2013. "This Home Is a Factory: Implications of the Maker Movement on Urban Environments." Craft + Design Enquiry 5. Accessed November 27, 2016.

http://press.anu.edu.au/apps/bookworm/view/craft+\%2B+design+enquiry\%3B+issue+5, $+2013 / 10761 /$ ch08.xhtml.

_ ., and Bradley Haylock. 2012. "Designer/Maker: The Rise of Additive Manufacturing, Domestic-Scale Production and the Possible Implications for the Automotive Industry." Computer-Aided Design \& Applications, PACE 2: 33-48.

Rifkin, Jeremy. 2012. "The Third Industrial Revolution: How the Internet, Green Electricity, and 3-D Printing Are Ushering in a Sustainable Era of Distributed Capitalism." World Financial Review, March 3. Accessed November 27, 2016. www.worldfinancialreview.com/?p=2271.

- 2011, The Third Industrial Revolution: How Lateral Power is Transforming Energy, the Economy, and the World. New York: Palgrave Macmillan.

Rigi, Jakob. 2013. "Peer Production and Marxian Communism: Contours of a New Emerging Mode of Production." Capital \& Class 37 (3): 397-416.

Rundle, Guy. 2014. A Revolution in the Making: 3D Printers, Robots and the Future. Melbourne: Affirm Press.

Schumacher, E.F. 1973. Small Is Beautiful: A Study of Economics as If People Mattered. London: Abacus. 
Seepersad, Carolyn C. 2014. "Challenges and Opportunities in Design for Additive Manufacturing." 3D Printing and Additive Manufacturing 1 (1): 10-3.

Söderberg, Johan. 2013. "Automating Amateurs in the 3D Printing Community - Connecting the Dots between Deskilling and User-Friendliness." Work Organisation, Labour and Globalisation 1 (1): 124-40.

- 2014. "Reproducing Wealth Without Money, One 3D Printer at a Time: The Cunning of Instrumental Reason." Journal of Peer Production 4: 1-10.

Stein, Jesse Adams. 2016. Hot Metal: Material Culture and Tangible Labour. Manchester University Press. Manchester.

- 2015. "Making 'Foreign Orders': Australian Print-Workers and Clandestine Creative Production in the 1980s." Journal of Design History 28 (3): 275-92.

Taylor, Charles. 2003. Modern Social Imaginaries. Durham, N.C.: Duke University Press.

Tocchetti, Sara. 2012. 'DIYbiologists as 'Makers' of Personal Biologies: How MAKE Magazine and Maker Faires Contribute in Constituting Biology as a Personal Technology." Journal of Peer Production 2: 1-9.

Tonkinwise, Cameron. 2014. "Design's (Dis)Orders \& Transition Design." Draft. Accessed November 27, 2016.

www.academia.edu/11791137/Design_Dis_Orders_Transition_Design_as_Postindustria 1_Design.

Troxler, Peter. 2010. "Commons-Based Peer-Production of Physical Goods Is There Room for a Hybrid Innovation Ecology?" Conference proceedings. Third Free Culture Research Conference. Berlin.

_. 2013. "Making the Third Industrial Revolution - The Struggle for Polycentric Structures and New Peer-Production Commons in the FabLab Community." In WalterHerrmann, Julia, and Büching, Corinne (eds) FabLab: Of Machines, Makers and Inventors, 181-98. Bielefeld: Transcript.

_., and Caspar van Woensel. 2013. "Socio-technical Changes Brought About by ThreeDimensional Printing Technology." Conference proceedings, 3D Printing: Destiny, Doom or Dream?, Leiden, 188-208.

Tumbleston, John R., et al. 2015. "Continuous Liquid Interface Production of 3D Objects." Science 347 (6228): 1349-52.

Vanni, Ilaria. 2015, “ 'Why Save the World When You Can Design It?' Precarity and Fashion in Milan." Fashion Theory 7419: 1-20.

Walter-Herrmann, Julia. 2013. "FabLabs - A Global Social Movement?" In FabLab, 33-46. . and Büching, Corinne. 2013. "Introduction." In FabLab, 9-26.

Weinberg, Michael. 2010. "It Will be Pretty Awesome if They Don't Screw it Up: 3D Printing, Intellectual Property and the Fight Over the Next Great Disruptive Technology.” Public Knowledge (November): 1-15. Accessed November 27, 2016. www.publicknowledge.org/files/docs/3DPrintingPaperPublicKnowledge.pdf.

\section{Notes}

${ }^{1}$ This phenomena is also discussed in Birtchnell and Urry 2012; Birtchnell and Hoyle 2014, 2; Ratto and Ree 2012; Bastani 2012.

${ }^{2}$ The notion of political imaginaries has been used by science and technology studies to unpack how the public understands and responds to technological change. For example, Phil McNaughton and Julia S. Guivant (2011) examined the diverse political imaginaries prompted by nanotechnology, finding that such imaginaries took shape along national lines. Helga Nowotny (2014) found that public understandings of science can be usefully 
apprehended in relation to political imaginaries, and that an understanding of such imaginaries will lead to better communication with the public about science issues.

${ }^{3}$ Some examples of measured analysis of 3D printing's future include (but are not limited to): Ratto and Ree 2012; Söderberg 2014; Birtchnell and Urry 2013, 2016; Majewski 2014; Heemsbergen et. al. 2016).

${ }^{4}$ These include ultra-libertarian visions (see Record et. al. 2015). Although not as common in mainstream or academic discourse, more pessimistic or cautionary visions of 3D printing's future do exist (see for example Neely 2014; Arieff 2014; Heemsbergen 2014; Weinberg 2010; Daly 2016. See also analysis in Fordyce 2015). The concerns include environmental damage, poorly-made and defective products designed by amateurs, and emerging socio-legal quandaries related to copyright and intellectual property.

${ }^{5}$ The notion of adding layers to create a three-dimensional form has been traced back to nineteenth century topography and photosculpture, and 1970s-era experiments with the additive manufacturing process that used a deposition method (Bourell et. al. 2009).

${ }^{6}$ Mark Hatch is the CEO and founder of Tech Shop, an international chain of member-based workshops.

${ }^{7}$ In June 2015 Bre Pettis left Stratasys, taking the company Bold Machines with him but leaving Makerbot under Stratasys' ownership.

${ }^{8} 3 \mathrm{D}$ printing has also been positioned as a savior for poverty-stricken communities in the Global South (see Birtchnell and Hoyle 2014).

${ }^{9}$ There is a great deal more that can be said about the issue of employment and future technologies (including 3D printing), but it falls outside the scope of this article.

${ }^{10}$ For further discussion of the "country that makes things" debate, see Gibson, Carr and Warren 2012.

${ }^{11}$ The RepRap can self-replicate with one caveat: the maker still needs to purchase auxiliary hardware supplies for some parts.

${ }^{12}$ For example United States President Barack Obama's 2013 State of the Union address. 